\begin{tabular}{c}
\hline TÜRK \\
TARIM ve DOĞA BiLIMLERI \\
DERGISi \\
\hline \hline
\end{tabular}

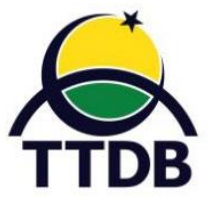

www.dergipark.gov.tr/turkjans

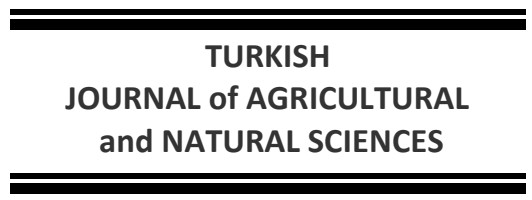

Araştırma Makalesi

\title{
Zeytin (Olea europaea) Yaprağı Ekstraktının Model Organizma Galleria mellonella Hemosit Aracılı Bağışıklık Tepkileri Üzerine Etkileri
}

\author{
Serhat KAYA*, Neslihan DEMiR \\ Çanakkale Onsekiz Mart Üniversitesi Fen-Edebiyat Fakültesi Biyoloji Bölümü, Terzioğlu Yerleşkesi, \\ Çanakkale \\ *Sorumlu yazar: serhatkaya@comu.edu.tr
}

Geliş Tarihi: 19.02.2020 Düzeltme Geliş Tarihi: 15.05.2020 Kabul Tarihi: 22.05.2020

$\overline{\text { Öz }}$

Zeytin ağacı (Olea europaea) ülkemizin de içerisinde yer aldığı Akdeniz bölgesinde yaygın olarak yetiştirilen bir türdür. Bu ağacın meyvesi ve yağından yararlanıldığı kadar, yapraklarından da halk hekimliğinde yararlanılmaktadır. Antioksidan, anti-enflamatuar ve antibiotik etkilerinin yanında kalp hastalıklarından korunma, karaciğer yağlanması, diabet gibi bazı yaygın hastalıklara karşı da etkili olduğu bilinmektedir. Zeytin yaprağının en önemli bileşeni oleuropeindir. Çalışmamızda; insan patojenleri için sıklıkla kullanılan model organizma Galleria mellonella (Büyük Balmumu Güvesi) kullanıldı. Zeytin yaprağı ekstraktı ile muamele edilen G. mellonella larvalarında toplam hemosit sayısı, enkapsülasyon ve melanizasyon bağışıklık tepkileri incelendi. Toplam hemosit sayısının tespiti ve enkapsülasyonmelanizasyon tepkilerinin belirlenmesi için faz-kontrast mikroskobu kullanıldı. Bulgularımıza göre 1000 ppm dozunda zeytin yaprağı ekstraktı bağışıklığı desteklemektedir.

Anahtar kelimeler: Zeytin yaprağı ekstraktı, Oleuropein, Galleria mellonella, hemosit, enkapsülasyon, melanizasyon

\section{Effects of Olive (Olea europaea) Leaf Extract on Hemocyte-Mediated Immune Responses of The Model Organism Galleria mellonella}

\begin{abstract}
Olive tree (Olea europaea) is a species widely grown in the Mediterranean region, where our country is located. As well as the fruit and oil of this tree, its leaves are used in folk medicine. In addition to its antioxidant, anti-inflammatory and antibiotic effects, it is known to be effective against some common diseases such as protection from heart disease, fatty liver and diabetes. The most important component of olive leaf is oleuropein. In our study; the model organism Galleria mellonella (Greater Wax Moth), which is frequently used for human pathogens has been used. The effects of olive leaf extract treated to $G$. mellonella larvae on total hemocyte count, encapsulation and melanization immune responses were investigated. A phase-contrast microscope was used to determine the total hemocyte count and the encapsulation-melanization responses. According to our findings, $1000 \mathrm{ppm}$ dose of olive leaf extract supports immunity.
\end{abstract}

Keywords: Olive leaf extract, Oleuropein, Galleria mellonella, hemocyte, encapsulation, melanization

\section{Giriş}

Zeytin ağacının (Olea europaea) kökeni Akdeniz bölgesidir ve çağlar boyunca meyvesinden, yağından ve yapraklarından çeşitli şekillerde faydalanılmıştır. Zeytin yaprağı metabolizma üzerine yararlı etkileri nedeniyle geleneksel ilaç olarak kullanılmakta ve zeytin yaprağının bu özellikleri fenolik içeriği ile alakalıdır (El ve Karakaya, 2009). Bu fenolik içerikler hastalık direncinde önemli bir rol oynamaktadırlar (Servili ve Montedoro, 2002; Antolovich ve ark., 2000). Zeytin yaprağı 
özütünün ana bileşenleri oleuropein ve hidroksitirozol'dür (Persia ve ark., 2014). Silva ve ark. (2006)'ya göre en yüksek toplam fenolik içerik kuru zeytin yaprağında bulunmuştur. Çalışmalar oleuropeinin; antimikrobiyal (Furneri ve ark., 2002), antialerjik (Mwakalukwa ve ark., 2019), antigenotoksik (Geyikoğlu ve ark., 2017), antienflamatuar (Geyikoğlu ve ark., 2017; Yin ve ark., 2019), antioksidan (Geyikoğlu ve ark., 2017; Yin ve ark., 2019), antidiabetik (Park ve ark., 2013) ve antiapoptotik (Yin ve ark., 2019) özellikleri olduğunu göstermektedir. Yapılan bazı çalışmalara göre bir fenolik bileşik olan oleuropeinin HeLa hücrelerinde apoptozu indüklediği gösterilmiştir (Yao ve ark., 2014). Oleuropeince zengin ekstraktların antikanser özellik gösterdiği çeşitli çalışmalarla ortaya konulmuştur (Sirianni ve ark., 2010; MartínezMartos ve ark., 2014). Oleuropein tedavilerinin kalp fonksiyonlarını iyileştirerek myokardit tedavisine yeni bir bakış açısı getireceği düşünülmektedir (Zhang ve ark., 2017). Omar (2010)'a göre literatürde oleuropeinin kardiyoprotektif rolü ve kroner kalp hastalıklarının tedavisinde kullanımı ile alakalı çok sayıda çalışma bulunmaktadır. Oleuropeinin toplam lenfosit sayısında belirgin bir artışa sebep olduğu ve insan periferal bağışıklık yanıtlarının düzenlenmesinde etkili olduğu belirlenmiştir (Magrone ve ark., 2018). Giamarellos-Bourboulis ve ark. (2006) çalışmalarında oleuropeinin fagositozu arttırarak bağışıklığı desteklediği ve umut verici bir immünomodülatör olduğu sonucuna ulaşmışlardır. Bütün canlılarda bağışıklık, beslenme ve üreme ile birlikte hayatta kalmanın kilit unsurudur. Böcekler ve memeliler, hem humoral hem de hücresel tepkileri içeren eski bir doğal bağışıklık sistemini paylaşır ve bu bize doğuştan gelen bağışıklık sisteminin kökenini anlamak için eşsiz fırsatlar tanımaktadır (Vilmos ve Kurucz, 1998; Krautz ve ark., 2014; Cutuli ve ark., 2019). Böcek bağışıklığına ilişkin çalışmalar, memeli deneklerde patojen virülansını değerlendirmek için yapılan çalışmalarla karşılaştırılabilir sonuçlar ortaya koymaktadır (Sheehan ve ark., 2018). Son çalışmalar böceklerde de edinsel bağışıklık olabileceğini göstermektedir (Tassetto ve ark., 2017). Hemositler, böcek bağışıklığında kemotaksis ve fagositoz da dahil olmak üzere önemli affektör ve efektör rolleriyle omurgalı makrofajları ile analogtur (De Filippo ve Beck, 2018). Lepidopterlerde; mikrobiyal enfeksiyonlara karşı erken tepki oluşturmak için hemosit tiplerinden özellikle, plazmatositler ve granülositler görev alır (De Filippo ve Beck, 2018). Granülositler ve plazmatositler dolaşımdaki hemositlerin yarısından fazlasını oluşturmaktadır ve enkapsülasyonda aktif görevleri vardır (Jiravanichpaisal ve ark., 2006). Böceklerde en etkili humoral bağışıklık yanıtlarından biri melanizasyon yanıtıdır (Lee ve Anstee, 1995). Melanin oluşumuna neden olan biyokimyasal yolakların büyük bir kısmı hem memelilerde hem de böceklerde ortaktır (Nappi ve Christensen, 2005). Son yıllarda omurgasız model organizmalarla yapılan çalışmalar önem kazanmaktadır. Omurgasız model organizmalar; kolay ve çok sayıda üretilebilmeleri, bakım maliyetlerinin azlığı, uygulamada kolaylıkları ve hızlı sonuç vermeleri nedeni ile tercih sebebidir. Yaygın olarak insan patojenleri için omurgasız model organizma olarak kullanılan türlerden bir tanesi de Galleria mellonella'dır (Champion ve ark., 2009; Mukherjee ve ark., 2010; Loof ve ark., 2011; Junqueira, 2012; Cook ve McArthur, 2013; Martinez-Martos ve ark., 2014; Ignasiak ve Maxwell, 2017; Sigle ve Hillyer, 2018). Bağışıklık ile ilgili çalışmalarda model organizma olarak kullanılan G. mellonella (Eguchi ve Iwabuchi, 2006; Mukherjee ve ark., 2010; Cook ve McArthur, 2013) kolay çoğaltılması ve uygulama sonuçlarının çabuk elde edilmesi nedeni ile tercih edilmektedir. Bağışıklık parametrelerinin $G$. mellonella larvalarında uyaran şiddetine bağlı ve primer ajanın yapısına orantılı yanıtlar oluşturduğu (Wu ve ark., 2016); humoral bağışıklıkta sadece patojene bağlı moleküler paternlerinin değil aynı zamanda endojen immün peptidlerinin de önemli olduğu belirlenmiştir (Altincicek ve ark., 2007). Toplam ve farklı hemosit sayıları üzerine yapılan çalışmalar hemosit sayısının bağışıklıkta önemli bir faktör olduğunu göstermektedir (Altuntaş ve ark., 2012; Er ve Keskin, 2015; Sezer ve Özalp, 2015; Er ve ark., 2017; Duman ve Altuntaş, 2018; Yücel ve Kayış, 2018). Zeytin yaprağı, çeşitli hastalıklara iyi geldiği gerekçesi ile alternatif tıp uygulamalarında kullanılmaktadır. Yapılan bu çalışma ile oleuropeince zengin zeytin yaprağı ekstraktının G. mellonella bağışıklık sistemi üzerindeki doza bağlı etkilerinin ortaya çıkartılması amaçlanmıştır. 


\section{Materyal ve Yöntem \\ Ekstrakt ve dozların hazırlanması}

Toplanan zeytin yaprağı örnekleri oda sıcaklığında kurutulmuştur. Kurutulmuş yapraklar öğütücü ile toz haline getirilerek Yateem ve ark. (2014) çalışmalarında belirtilen $\% 80$ etil alkol çözücüsüyle soksilet cihazında ekstrakte edilmiştir. Bu işlem sonrasında alkol uzaklaştırılarak ekstraktın kuru hali alınmış ve amber şişede $+4{ }^{\circ} C^{\prime}$ de saklanmıştır. Deney için kuru madde \%40 Dimetil Sülfoksit (DMSO) içerisinde, dozları 1000, 2500, 5000 ve 10000 ppm olacak şekilde hazırlanmıştır.

\section{Deneklerin yetiştirilmesi}

G. mellonella larvaları Çanakkale Onsekiz Mart Üniversitesi Fen-Edebiyat Fakültesi Biyoloji bölümü Böcek Fizyolojisi araştırma laboratuvarında yetiştirildi. Deneklerin yetirştirilmesi için Kaya (2015) yöntemi izlenmiştir. Onbeş gün sonra yumurtadan çıkan larvalar gözlemlendiğinde Bronskill (1961) tarafından geliştirilip Sak ve ark. (2006) tarafından içeriği değiştirilen yapay besinden (doğal kararmış petek, buğday kepeği, bal, su ve gliserin) $10 \mathrm{gr}$ eklenerek larvalar beslenmeye alınmıştır. Son evreye ulaşan larvalar $(0.18 \pm$ $0.02 \mathrm{gr}$ ) deneyde kullanılmak üzere seçilmiştir.

\section{Deney dozlarının uygulanması}

Deney için seçilen $G$. mellonella larvalarına yüzey sterilizasyonu için $\% 70$ etil alkol püskürtülmüştür. Sterilize edilen larvalar buz kasetleri üzerine konarak hareketsiz kalmaları sağlanmıştır. Hareketsiz kalan örnekler stereo mikroskop (Olympus, SZ20, Japan) altında sırt üstü yatırılmış ve deney dozları her bir örneğe $5 \mu$ l olacak şekilde proleglerinin en sonuncusundan mikroenjektör (Hamilton, USA) yardımıyla enjekte edilmiştir. Her bir doz için üç tekrar yapılmış olup, her tekrarda beş örnek kullanılmıştır $(n=15)$. Enjeksiyonların etkisini göstermesi için 24 saat beklenmiştir.

\section{Hemosit sayımı}

Hemosit sayımı için uygulama yapılan larvalar proleglerinin ön segmentinden bir iğne yardımıyla delinmiş ve buradan sızan hemolenften $4 \mu \mathrm{l}$ alınarak içerisinde $36 \mu \mathrm{l}$ antikoagulant bulunan mikrosantrifüj tüpüne konulmuştur (Kaya, 2015). Hücre agregasyonunu engellemek için pipetaj işlemi uygulanmıştır. Hazırlanan antikoagulanthemolenf karışımından $10 \mu$ alınarak Neubauer hemositometresi'ne (Marienfeld, Germany) yüklenmiş ve faz kontrast mikroskopta (Olympus BX-51, Japan) hücre sayımı yapılmıştır.

\section{Enkapsülasyon-melanizasyon deneyleri}

Enkapsülasyon-melanizasyon yanıtlarını provake etmek için doz uygulaması yapılan örneklere \%1'lik Coomassie Brilliant Blue-G 250 boyası ile boyanan Sephadex A-25 kromatografi boncukları $10 \mu \mathrm{l}$ Phosphate Buffered Saline (PBS) çözeltisi içerisinde ortalama 15-20 boncuk olacak şekilde enjekte edilmiştir. Enjeksiyonu takip eden 4. saat (kısa period) ve 24. saat (uzun period) sonunda larvalar stereo mikroskop altında disekte edilerek boncuklar toplanmıştır. Toplanan boncuklar faz-kontrast mikroskopta incelenerek Er ve ark. (2010)'a uygun olarak sınıflandırılmış ve enkapsülasyonmelanizasyon tepkileri değerlendirilmiştir (Uçkan ve ark., 2010).

\section{istatistiksel analiz}

Hemosit sayımı, enkapsülasyon ve melanizasyon deneylerinin her biri için üç tekrar yapılmış ve her tekrarda beş larva kullanılmıştır. Enkapsülasyon ve melanizasyon için 4. saat ve 24 . saat olmak üzere iki alt grup daha oluşturulmuştur. Örneklerden elde edilen veriler SPSS v20 programı ile one-way ANOVA (Tukey HSD) analizi yapılarak değerlendirilmiştir $(p<0.05)$.

\section{Bulgular ve Tartışma}

Çalışmanın sonucunda uygulama yapılmamış (kontrol) grup (19.71 $\times 10^{6}$ hücre/ml) ile DMSO enjeksiyonlu grup (18.61 x $10^{6}$ hücre/ml) arasında hemosit sayıları bakımından bir fark bulunmamıştır. Bununla birlikte tüm doz uygulamaları hem kontrol hem de DMSO enjeksiyonlu gruptan yüksek bulunmuştur. En yüksek hemosit ortalamasına sahip olan grup 5000 ppm doz enjeksiyonu yapılan gruptur (34.46 x $10^{6}$ hücre/ml). Zeytin yaprağı ekstraktı enjekte edilen gruplardaki en düşük ortalama 10000 ppm doz enjeksiyonu yapılan grupta tespit edilmiştir $\left(26.39 \times 10^{6}\right.$ hücre/ml) (Şekil 1). 


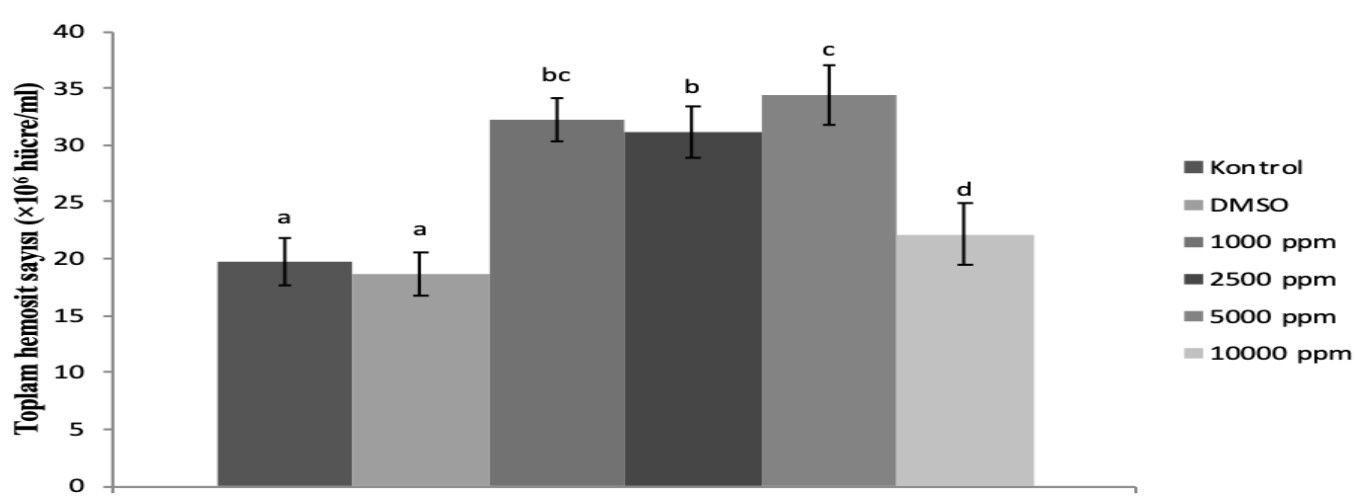

Şekil 1. Zeytin yaprağı ekstraktının G. mellonella larvası toplam hemosit sayısındaki değişime etkisi. Aynı harfleri taşıyan gruplar arasındaki fark önemsizdir. Her bir doz için toplam 15 örnek değerlendirilmiştir $(n=15)$

Elde edilen verilere göre hem 4 hem de 24 saatlik enkapsülasyon deneylerinde zayıf ve güçlü enkapsülasyon tepkilerinde anlamlı fark gösteren grup 1000 ppm doz enjeksiyonlu gruptur. Kontrol grubuna göre DMSO enjeksiyonlu gruplar 4 saatlik enkapsülasyon tepkilerini etkilemezken 24 saatlik enkapsülasyon tepkilerini anlamlı oranda azaltmıştır (Çizelge 1).

Çizelge 1. Zeytin yaprağı ekstraktının, G. mellonella larval enkapsülasyon tepkilerine (\%) etkisi

\begin{tabular}{|c|c|c|c|}
\hline \multirow{2}{*}{ Ekstrakt } & \multicolumn{3}{|c|}{4 saat $(\%$ Ort $\pm \mathrm{SH}) * * *$} \\
\hline & Olmamış & Zayıf & Güçlü \\
\hline Kontrol & $09.57 \pm 1.95^{\mathrm{a}}$ & $79.66 \pm 2.51^{\mathrm{a}}$ & $10.77 \pm 2.11^{a}$ \\
\hline DMSO & $12.84 \pm 1.92^{\mathrm{a}}$ & $78.79 \pm 2.70^{a}$ & $08.37 \pm 1.99^{a}$ \\
\hline 1000 ppm & $16.43 \pm 4.87^{a}$ & $62.46 \pm 5.32^{\mathrm{b}}$ & $21.10 \pm 2.73^{b}$ \\
\hline 2500 ppm & $19.38 \pm 5.23^{a}$ & $72.34 \pm 4.57^{\mathrm{ab}}$ & $08.27 \pm 2.26^{a}$ \\
\hline 5000 ppm & $24.76 \pm 3.48^{a}$ & $67.47 \pm 3.46^{\mathrm{ab}}$ & $07.77 \pm 1.58^{a}$ \\
\hline 10000 ppm & $17.52 \pm 2.48^{a}$ & $79.42 \pm 3.06^{\mathrm{a}}$ & $03.06 \pm 1.08^{a}$ \\
\hline \multirow{2}{*}{ Ekstrakt } & \multicolumn{3}{|c|}{24 saat $(\%$ Ort $\pm \mathrm{SH}) * * *$} \\
\hline & Olmamış & Zayıf & Güçlü \\
\hline Kontrol & $9.55 \pm 1.47^{a}$ & $28.28 \pm 1.93^{a}$ & $62.17 \pm 2.13^{a}$ \\
\hline DMSO & $3.16 \pm 1.78^{\mathrm{cb}}$ & $74.56 \pm 4.40^{b}$ & $22.29 \pm 4.57^{b}$ \\
\hline 1000 ppm & $0.83 \pm 0.83^{c}$ & $61.24 \pm 5.76^{c}$ & $37.93 \pm 6.08^{c}$ \\
\hline 2500 ppm & $7.52 \pm 2.52^{\mathrm{ab}}$ & $71.65 \pm 3.71^{b c}$ & $20.38 \pm 3.03^{b}$ \\
\hline 5000 ppm & $4.25 \pm 0.96^{\mathrm{abc}}$ & $67.98 \pm 1.45^{\mathrm{bc}}$ & $27.77 \pm 1.34^{\mathrm{bc}}$ \\
\hline 10000 ppm & $2.20 \pm 0.90^{\mathrm{cb}}$ & $74.96 \pm 1.55^{b c}$ & $22.84 \pm 1.48^{\mathrm{b}}$ \\
\hline
\end{tabular}

*Aynı harfleri taşıyan gruplar arasındaki fark önemsizdir $(P>0.05)$.

**Her bir doz için ve her bir saat grubunda ayrı ayrı toplam 15 örnek değerlendirilmiştir $(n=30)$.

$* * * \mathrm{SH}=$ Standart Hata

Bulgularımıza göre DMSO kontrol grubuna göre melanizasyon tepkilerini azaltmıştır. Buna rağmen 1000 ve 2500 ppm doz enjeksiyon gruplarında 4. saatte DMSO enjeksiyonlu gruba göre melanizasyon tepkilerinde artış gözlemlenmiştir. Yirmidört saat enjeksiyon grubunda ise kontrole göre DMSO ve 1000 ppm enjeksiyon grupları dışında tüm dozlarda melanizasyon tepkisinde azalma tespit edilmiştir (Çizelge 2). Model organizma G. mellonella bağışıklığına ilişkin yapılan birçok çalışmada toplam hemosit sayısı önemli bir belirteç olarak değerlendirilmiştir ( $\mathrm{Er}$ ve ark., 2010; Altuntaş ve ark., 2012; Er ve Keskin, 2015; Kurt ve Kayış, 2015; Gwokyalya ve Altuntaş, 2019). Söz konusu literatürlerde genel olarak hemosit sayısındaki artış bağışıklığın desteklendiği şeklinde yorumlanmıştır. 
Çalışmamızda elde ettiğimiz veriler ışığında oleuropeinin belirli dozlarda hemosit sayısını arttırdığı, en yüksek dozlarda ise bu artışın azaldığı görülmüştür (Şekil 1). Magrone ve ark. (2018) yaptıkları çalışmada in vitro koşullarda oleuropeinin lenfosit sayısını arttırdığını tespit etmişlerdir. Çalışmamızın toplam hemosit sayısının değişimi ile ilgili verileri bu literatür bilgisi ile uyumludur. Bitki gelişim düzenleyicileri (BGD) ile yapılan çalışmalar [Absisik Asit, İndol-3-Asetik Asit (IAA) ve Giberellic Asit $\left(G A_{3}\right)$ ] BGD'lerin düşük dozlarda hemosit sayısını arttırırken, yüksek dozlarda hormeosis etkisi göstererek hemosit sayısını düşürdüğünü ortaya koymuştur (Altuntaş ve ark., 2012; Er ve Keskin, 2015; Kaya, 2015). Çalışmamızda da benzeri bir şekilde hemosit sayısının düşük dozlarda artış gösterirken yüksek dozlarda azalma göstermesi hormeosis etkisinden kaynaklanmaktadır. Enkapsülasyon bağışıklık tepkisi, hemosit aracılı bağışıklık tepkileri içerisinde en önemli verilerden birisidir. Hemositler fagosite edemeyecekleri kadar büyük yabancı cisimlerin etrafında kapsüllenme gerçekleştirmektedir.
Çalışmamızda kullanılan 1000 ppm dozunun güçlü enkapsülasyon tepkisini hem 4 hem de 24 saat deneylerinde arttırdığı tespit edilmiştir (Çizelge 1). Giamarellos-Bourboulis ve ark. (2006) oleuropeinin immünomodülatör olarak görev yapabileceği yönündeki bulguları ile çalışmamızın enkapsülasyon verileri örtüşmektedir. $\mathrm{GA}_{3}$ uygulamasının nekrotik ve apoptotik hücre sayısında artışa neden olduğu ve bu nedenle enkapsülasyon-melanizasyon tepkilerinde azalma meydana geldiği belirlenmiştir (Altuntaş ve ark., 2012). Humoral bağışıklık tepkilerinden biri olan melanizasyon, 4 saat sonunda DMSO, 5000 ppm ve 10000 ppm dozlarında kontrole göre daha az gerçekleşmiştir. Yirmidört saat sonunda ise 2500 ppm, 5000 ppm ve 10000 ppm dozlarında hem kontrol hem de DMSO ve 1000 ppm dozlarından daha az bir melanizasyon tepkisi göstermiştir (Çizelge 2). Bu sonuçlar zeytin yaprağı ekstraktının yüksek dozlarda melanizasyon tepkisini azalttığını göstermektedir. Bu durumun zeytin yaprağı içerisinde yer alan maddelerin antioksidan kapasitesinden kaynaklandığı düşünülmektedir.

Çizelge 2. Zeytin yaprağı ekstraktının G. mellonella larvasının melanizasyon tepkisine (\%) etkisi

\begin{tabular}{ccc}
\hline \hline \multirow{2}{*}{ Ekstrakt } & \multicolumn{2}{c}{4 saat $(\% \text { Ort } \pm \mathrm{SH})^{* * *}$} \\
\cline { 2 - 3 } Kontrol & Melanizasyon var & Melanizasyon yok \\
DMSO & $31.76 \pm 6.56^{\mathrm{a}}$ & $68.24 \pm 6.56^{\mathrm{a}}$ \\
$1000 \mathrm{ppm}$ & $06.73 \pm 3.30^{\mathrm{c}}$ & $93.27 \pm 3.30^{\mathrm{b}}$ \\
$2500 \mathrm{ppm}$ & $30.96 \pm 5.51^{\mathrm{ab}}$ & $69.04 \pm 5.51^{\mathrm{a}}$ \\
$5000 \mathrm{ppm}$ & $23.21 \pm 5.50^{\mathrm{abc}}$ & $76.79 \pm 5.50^{\mathrm{ab}}$ \\
$10000 \mathrm{ppm}$ & $11.27 \pm 4.26^{\mathrm{c}}$ & $88.73 \pm 4.26^{\mathrm{b}}$ \\
\hline Ekstrakt & $14.33 \pm 2.90^{\mathrm{cb}}$ & $85.67 \pm 2.90^{\mathrm{ab}}$ \\
\hline Kontrol & & \\
DMSO & Melanizasyon var & $36.35 \pm 4.76^{\mathrm{a}}$ \\
$1000 \mathrm{ppm}$ & $63.65 \pm 4.76^{\mathrm{a}}$ & $46.38 \pm 2.32^{\mathrm{ab}}$ \\
$2500 \mathrm{ppm}$ & $53.62 \pm 2.32^{\mathrm{ab}}$ & $44.75 \pm 3.55^{\mathrm{ab}}$ \\
$5000 \mathrm{ppm}$ & $55.26 \pm 3.55^{\mathrm{ab}}$ & $56.03 \pm 3.75^{\mathrm{b}}$ \\
$10000 \mathrm{ppm}$ & $43.97 \pm 3.75^{\mathrm{b}}$ & $51.99 \pm 3.35^{\mathrm{b}}$ \\
\hline
\end{tabular}

*Aynı harfleri taşıyan gruplar arasındaki fark önemsizdir ( $\mathrm{P}>0.05)$.

**Her bir doz için ve her bir saat grubunda ayrı ayrı toplam 15 örnek değerlendirilmiştir $(n=30)$.

$* * * \mathrm{SH}=$ Standart Hata

Bir bitki sekonder metaboliti olan azadirachtin uygulamasının da hemositlerde genotoksik etki ortaya çıkmasına ve hemosit sayısında azalmaya neden olduğu belirlenmiştir (Er ve ark., 2017; Duman ve Altuntaş, 2018).
Zeytin yaprağı da birçok sekonder metaboliti barındırmaktadır. Sekonder metabolitlerin genotoksik etkisi hemositlerde yüzey tanıma proteinlerinin bozulması, yayılma kapasitelerinin ve enzimatik üretim 
kapasitesinin azalması gibi işlev kaybına yol açması muhtemeldir. $\mathrm{Bu}$ durum da enkapsülasyon ve melanizasyon tepkilerindeki azalmayı açıklamaktadır.

Zeytin yaprağı ekstraktının hangi yollarla bağışıklık tepkilerini etkilediğinin belirlenmesi için antioksidan, genotoksik ve enzimatik etkilerinin belirleneceği ileri araştırmalar yapılması gerekmektedir. Bu yolla tam olarak hangi mekanizmanın etkilendiğinin ortaya konulması ve bunun muhtemel sonuçlarının sağlıklı olarak değerlendirilmesi mümkün olacaktır.

\section{Sonuç ve Öneriler}

Sonuç olarak, zeytin yaprağı ekstraktının 1000 ppm dozda bağışıklığı destekleyebileceği, daha yüksek dozlarda ise etkinliğinin azalacağı ortaya konulmuştur. Önceki çalışmalardan da görülebileceği üzere, doğuştan gelen böcek bağışıklığı ile doğuştan gelen memeli bağışıklığı birçok ortak nokta barındırmaktadır. Bu nedenle çalışmamızın sonuçlarına dayanarak belirli dozlarda zeytin yaprağı tüketiminin canlıların bağışıklığını destekleyeceğini kanaatine varılmıştır.

\section{Teşekkür}

$\mathrm{Bu}$ çalışma, Çanakkale Onsekiz Mart Üniversitesi, Bilimsel Araştırma Projeleri Koordinasyon Birimince (BAP) FHD-2018-2685 kodlu proje kapsamında desteklenmiştir.

\section{Kaynaklar}

Altincicek, B., Linder, M., Linder, D., Preissner, K.T. ve Vilcinskas, A. 2007. Microbial metalloproteinases mediate sensing of invading pathogens and activate innate immune responses in the lepidopteran model host Galleria mellonella. Infection and Immunity, 75(1): 175-183.

Altuntaş, H., Kılıç, A.Y., Uçkan, F. ve Ergin, E. 2012. Effects of gibberellic acid on hemocytes of Galleria mellonella L.(Lepidoptera: Pyralidae). Environmental Entomology, 41(3): 688696.

Antolovich, M., Prenzler, P., Robards, K. ve Ryan, D. 2000. Sample Preparation in the Determination of Phenolic Compounds in Fruits. Analyst, 125: 9891009.

Bronskill, J. 1961. A cage to simplify the rearing of the greater wax moth, Galleria mellonella (Pyralidae). Journal of Lepidopterists Society, 15(2): 102-104.

Champion, O.L., Cooper, I.A.M., James, S.L., Ford, D., Karlyshev, A., Wren, B.W., Duffield, M., Oyston, P.C.F. ve Titball, R.W. 2009. Galleria mellonella as an alternative infection model for Yersinia pseudotuberculosis. Microbiology, 155: 1516-1522.

Cook, S.M. ve McArthur J.D. 2013. Developing Galleria mellonella as a model host for human pathogens. Virulence, 4: 350353.

Cutuli, M. A., Petronio, G., Vergalito, F., Magnifico, I., Pietrangelo, L., Venditti, N. ve Di Marco, R. 2019. Galleria mellonella as a consolidated in vivo model hosts: New developments in antibacterial strategies and novel drug testing. Virulence, 10(1): 527-541.

De Filippo, J. ve Beck, G. 2018. Cytokines of Invertebrate Immunity. "Alınmıştır: Reference Module in Life Sciences, ELSEIVER, ISBN:978-0-12-809633-8.

Duman, E. ve Altuntaş, H. 2018. Genotoxicity of azadirachtin on Galleria mellonella L. (Lepidoptera: Pyralidae). Biological Diversity and Conservation, 773-0918.

Eguchi, D. ve Iwabuchi K. 2006. A new cell line from the wax moth Galleria mellonella Linne (Lepidoptera: Pyralididae). In Vitro Cellular \& Developmental BiologyAnimal, 42(1-2): 1-3.

EI, S.N. ve Karakaya, S. 2009. Olive tree (Olea europaea) leaves: potential beneficial effects on human health. Nutrition Reviews, 67(11): 632-638.

Er, A. ve Keskin, M. 2015. Influence of abscisic acid on the biology and hemocytes of the model insect Galleria mellonella (Lepidoptera: Pyralidae). Annals of the Entomological Society of America, 109(2): 244-251.

Er, A., Taşkıran, D. ve Sak, O. 2017. Azadirachtin-induced effects on various life history traits and cellular immune reactions of Galleria mellonella (Lepidoptera: Pyralidae). Archives of Biological Sciences, 69(2): 335-344.

Er, A., Uçkan, F., Rivers, D.B., Ergin, E. ve Sak, O. 2010. Effects of parasitization and envenomation by the endoparasitic wasp Pimpla turionellae (Hymenoptera: Ichneumonidae) on hemocyte numbers, morphology, and viability of its host 
Galleria mellonella (Lepidoptera: Pyralidae). Annals of the Entomological Society of America, 103(2): 273-282.

Furneri, P.M., Marino, A., Saija, A., Uccella, N. ve Bisignano, G. 2002. In vitro antimycoplasmal activity of oleuropein. International Journal of Antimicrobial Agents, 20: 293-296.

Geyikoğlu, F., Emir, M., Çolak, S., Koç, K., Türkez, H., Bakır, M. ve Özek, N.S. 2017. Effect of oleuropein against chemotherapy drug-induced histological changes, oxidative stress, and DNA damages in rat kidney injury. Journal of Food and Drug Analysis, 25(2): 447-459.

Giamarellos-Bourboulis, E.J., Geladopoulos, T., Chrisofos, M., Koutoukas, P., Vassiliadis, J., Alexandrou, I., Tsaganos, T., Sabracos, L., Karagianni, V., Pelekanou, E.,Tzepi, I., Kranidioti, H., Koussoulas, V. ve Giamarellou, H. 2006. Oleuropein: a novel immunomodulator conferring prolonged survival in experimental sepsis by Pseudomonas aeruginosa. Shock, 26(4):410-416.

Gwokyalya, R. ve Altuntaş, H. 2019. Boric acidinduced immunotoxicity and genotoxicity in model insect Galleria mellonella L.(Lepidoptera: Pyralidae). Archives of Insect Biochemistry and Physiology, 101: e21588.

Ignasiak, K. ve Maxwell, A. 2017. Galleria mellonella (greater wax moth) larvae as a model for antibiotic susceptibility testing and acute toxicity trials. BMC Res Notes, 10: 428-436.

Jiravanichpaisal P., Lee B. ve Soderhall K. 2006. Cell-mediated immunity in arthropods: Hematopoiesis, coagulation, melanization and opsonization, Immunobiology, 211: 213-236.

Junqueira, J.C. 2012. Galleria mellonella as a model host for human pathogens: Recent studies and new perspectives. Virulence, 3:6, 474-476.

Kaya, S. 2015. Konağa Verilen İndol-3-Asetik Asitin ve Kaliks Sıvısının Konak Galleria mellonella L. (Lepidoptera: Pyralidae) ve Parazitoid Pimpla turionellae L. (Hymenoptera: Ichneumonidae) Hemositlerine Etkisi, Çanakkale Onsekiz Mart Üniversitesi Fen Bilimleri Enstitüsü Biyoloji Ana Bilim Dalı, Doktora Tezi, Çanakkale, s. 98.
Krautz, R., Arefin, B. ve Theopold, U. 2014. Damage signals in the insect immune response. Frontiers in Plant Science, 5: 342.

Kurt, D. ve Kayış, T. 2015. Effects of the pyrethroid insecticide deltamethrin on the hemocytes of Galleria mellonella. Turkish Journal of Zoology, 39(3): 452457.

Lee, M.J. ve Anstee, J.H. 1995. Phenoloxidase and its zymogen from the haemolymph of larvae of the lepidopteran Spodoptera littoralis (Lepidoptera: Noctuidae). Comparative Biochemistry and Physiology Part B: Biochemistry and Molecular Biology, 110(2): 379-384.

Loof, T.G., Schmidt, O., Herwald, H. ve Theopold, U. 2011. Coagulation Systems of Invertebrates and Vertebrates and Their Roles in Innate Immunity: The Same Side of Two Coins? Innate Immunity, 3: 34-40.

Magrone, T., Spagnoletta, A., Salvatore, R., Magrone, M., Dentamaro, F., Russo, M.A. ve Jirillo, E. 2018. Olive leaf extracts act as modulators of the human immune response. Endocrine, Metabolic \& Immune Disorders-Drug Targets, 18(1): 85-93.

Martinez-Martos, J.M., Mayas, M.D., Carrera, P., de Saavedra, J.M.A., Sánchez-Agesta, R., Arrazola, M. ve Ramírez-Expósito, M.J. 2014. Phenolic compounds oleuropein and hydroxytyrosol exert differential effects on glioma development via antioxidant defense systems. Journal of Functional Foods, 11: 221-234.

Mukherjee, K., Altincicek, B., Hain, T., Domann, E., Vilcinskas, A. ve Chakraborty, T. 2010. Galleria mellonella as a Model System for Studying Listeria Pathogenesis. Applied and Environmental Microbiology, 76(1): 310-317.

Mwakalukwa, R., Ashour, A., Amen, Y., Niwa, Y., Tamrakar, S., Miyamoto, T. ve Shimizu, K. 2019. Anti-allergic activity of polyphenolic compounds isolated from olive mill wastes. Journal of Functional Foods, 58: 207-217.

Nappi, A.J. ve Christensen, B.M. 2005. Melanogenesis and associated cytotoxic reactions: applications to insect innate immunity. Insect Biochemistry and Molecular Biology, 35(5): 443-459. 
Omar, S.H. 2010. Oleuropein in olive and its pharmacological effects. Scientia Pharmaceutica, 78(2): 133-154.

Park, J.H., Jung, J.H., Yang, J.Y. ve Kim, H.S. 2013. Olive leaf down-regulates the oxidative stress and immune dysregulation in streptozotocin-induced diabetic mice. Nutrition Research, 33(11): 942-951.

Persia, F.A., Mariani, M.L., Fogal, T.H. ve Penissi, A.B. 2014. Hydroxytyrosol and oleuropein of olive oil inhibit mast cell degranulation induced by immune and nonimmune pathways. Phytomedicine, 21(11): 1400-1405.

Sak, O., Uçkan, F. ve Ergin E. 2006. Effects of cypermethrin on total body weight, glycogen, ptotein and lipid contents of Pimpla turionellae (L.) (Hymenoptera: Ichneumonidae). Belgian Journal of Zoology, 136: 53-58

Servili, M. ve Montedoro G.F. 2002. Contribution of phenolic compounds to virgin olive oil quality. European Journal of Lipid Science and Technology, 104: 602-613.

Sezer, B. ve Özalp, P. 2015. Effects of pyriproxyfen on hemocyte count and morphology of Galleria mellonella. Fresenius Environmental Bulletin, 24(2): 621-625.

Sheehan, G., Garvey, A., Croke, M. ve Kavanagh, K. 2018. Innate humoral immune defences in mammals and insects: The same, with differences? Virulence, 9(1): 1625-1639.

Sigle, L.T. ve Hillyer, J.F. 2018. Mosquito Hemocytes Associate With Circulatory Structures That Support Intracardiac Retrograde Hemolymph Flow. Frontier in Physiology, 9: 1187.

Silva, S., Gomes, L., Leitao, F., Coelho, A.V. ve Boas, L.V. 2006. Phenolic compounds and antioxidant activity of Olea europaea L. fruits and leaves. Food Science and Technology International, 12(5): 385-395.

Sirianni, R., Chimento, A., De Luca, A., Casaburi, I., Rizza, P., Onofrio, A. ve Pezzi, V. 2010. Oleuropein and hydroxytyrosol inhibit MCF-7 breast cancer cell proliferation interfering with ERK1/2 activation. Molecular Nutrition \& Food Research, 54(6): 833-840.
Tassetto, M., Kunitomi, M. ve Andino R. 2017. Circulating immune cells mediate a systemic RNAi based adaptive antiviral response in Drosophila. Cell, 169(2): 314-325.

Uçkan, F., Er, A., ve Ergin, E. 2010. Levels of encapsulation and melanization in Galleria mellonella (Lepidoptera: Pyralidae) parasitized and envenomated by Pimpla turionellae (Hymenoptera: Ichneumonidae). Journal of Applied Entomology, 134: 718-726.

Vilmos, P. ve Kurucz É. 1998. Insect immunity: evolutionary roots of the mammalian innate immune system. Immunology Letters, 62: 59-66.

Wu, G., Xu, L. ve Yi, Y. 2016. Galleria mellonella larvae are capable of sensing the extent of priming agent and mounting proportionatal cellular and humoral immune responses. Immunology Letters, 174: 45-52.

Yao, J., Wu, J., Yang, X., Yang, J., Zhang, Y. ve $\mathrm{Du}$, L. 2014. Oleuropein induced apoptosis in HeLa cells via a mitochondrial apoptotic cascade associated with activation of the c-Jun NH2-terminal kinase. Journal of Pharmacological Sciences, 125(3): 300311.

Yateem, H., Afaneh, I. ve Al-Rimawi, F. 2014. Optimum conditions for oleuropein extraction from olive leaves. International Journal of Appiled Science and Technology, 4(5): 153-157

Yin, M., Jiang, N., Guo, L., Ni, Z., Al-Brakati, A.Y., Othman, M.S. ve Kassab, R.B. 2019. Oleuropein suppresses oxidative, inflammatory, and apoptotic responses following glycerol-induced acute kidney injury in rats. Life Sciences, 232: 116634.

Yücel, M.S. ve Kayış, T. 2018. Imidacloprid induced alterations in oxidative stress, biochemical, genotoxic and immunotoxic biomarkers in nonmammalian model organism Galleria mellonella L. (Lepidoptera: Pyralidae). Journal of Environmental Science and Health, Part B, 1-8.

Zhang, J.Y., Yang, Z., Fang, K., Shi, Z.L., Ren, D.H. ve Sun, J. 2017. Oleuropein prevents the development of experimental autoimmune myocarditis in rats. International Immunopharmacology, 48: 187-195. 